\title{
An Investigation into the Impact of Mindful- ness Education on Children Development - Based on the Mindfulness Experiment on 5th Graders of D primary School in W City
}

\author{
Jing Xie, Yanguo Tu \\ Hubei Normal University, Huangshi, China \\ Central China Normal University, Wuhan, China
}

\begin{abstract}
This study selected fifth graders from D Primary School as subjects and conducted a 12-week mindfulness education experiment using a pre-and post-test control experiment design. The results can be used to demonstrate that mindfulness education has a significant impact on children's attention development, emotional balance and development, psychological development and happiness enhancement. These aspects interact with each other to jointly improve the overall development level of children. Therefore, activities of mindfulness education are necessary and should be carried out moderately at school, thus giving full play to the positive role of mindfulness education in child development.
\end{abstract}

Best Evid Chin Edu 2019; 2(2):229-242.

Doi: 10.15354/bece.19.ar1049

Keywords: Mindfulness Education; Child Development; Educational Experiments

Correspondence to: Yanguo Tu, Professor at College of Education, Central China Normal University, China. Email: tuyg@mail.ccnu.edu.cn.

About the Author: Jing Xie, a Lecturer at College of Education Science, Hubei Normal University, China. Email: xiejing1302@163.com.

Conflict of Interests: None. 
$\mathrm{I}$ $\mathrm{N}$ the past ten years, with the rise of the mindfulness movement, training that appeals to the improvement of attention, mental health development and emotional regulation has been increasingly discovered and valued by scholars at home and abroad. Mindfulness education is not a fixed course or teaching mode, but refers to various educational activities carried out using mindfulness methods, such as mindfulness reading, mindfulness awareness, mindfulness writing, mindfulness lectures, and mindfulness eating, etc. The United States has implanted mindfulness training into the "K-12" education system. The UK's mindfulness campus program has benefited more than 7,000 children. The Dutch mindfulness upbringing program has had a positive impact on the communication between children and parents. The study of mindfulness in China has just started. Researchers have realized that mindfulness training has important values in school education to improve children's attention, shape children's moral quality, promote children's self-regulation, and enhance subjective well-being of teachers and students. In this study, students of grade five in an elementary school were selected to conduct a 12-week mindfulness education experiment using a pre- $\&$ post-test control experiment design, attempting to reveal the specific effects of mindfulness education on development of children.

\section{Research Methodology}

The theoretical hypothesis of this study is that experimental interventions through the mindfulness education curriculum adapted from cognitive therapy can effectively promote the development of children's psychological, social, emotional and cognitive aspects, thus improving the overall development level of children. The research mainly incorporates the combined method of educational experiment and measurement. The educational experiment adopts the pre- and post-test control experiment design of equal groups. The measurement tools include the "Attention Stability Questionnaire," the "Psychological Health Scale for Primary School Students," the "Positive and Negative Emotion Scales," and the "Index of Well-being."

\section{Subjects}

D Elementary School in W city is a small-scale school with no more than 35 students in each class. The number of students is conducive to the control and implementation of the experiment. In addition to the changes in body growth, children of the fifth grade begin to have more various feelings and emotions than before. Compared with children in the early period of primary school, older students can analyze and integrate external affairs in a more detailed manner and regulate their behavior (Zhang, 2004). In summary, after a careful discussion between the researcher and the principal of the experimental school and the head teachers, Class 1, Grade 5 was selected as the experimental group, and Class 2, Grade 5 was used as the control group. The two classes were equal in number and the two classes included typical students, head teachers and classroom teachers. Under the existing manpower and material resources, such class size and class level are just in line with the number and standards of subjects expected by the researcher. 
There were 20 male students and 11 female students in the experimental group, and one of them is an exceptional child. During the experiment, 4 students either took time off at different times or had events affecting their body and mind within one week to two weeks before the test. After excluding the influence of irrelevant variables, a total of 26 valid samples were obtained. In the control group, there were 19 male students and 12 female students. The subjects who did not meet the requirements were deleted, and a total of 29 valid samples were obtained. The quantity of final samples obtained is shown in Table 1. There are 32 boys and 23 girls in the valid sample.

\section{Research Design}

The experiment used two types of designs. One is the experimental design of the experimental group and the control group between the subjects; the other is the experimental design of the experimental group before and after the test. Using the mindfulness education course as the intervention method, and the fifth grade students of D Primary School as subjects of the study, quasi-experimental design was adopted as the research design.The researchers conducted pre- and post-intervention and pre- and postintervention tests in the class with both the experimental group and the control group. The dependent variable was the total score of each scale before and after the pre- \& post-tests of experimental group and the control group.

In order to control the interference of irrelevant and additional variables and reduce the experimental error as much as possible, this study adopted a variety of technical treatment methods: (i) The number of students, the sex ratio, and the family background of the experimental group and the control group were roughly balanced. (ii) During the experiment period, the teaching methods of the teachers in the experimental group and the control group were the same as before, and they were consistent with the school teaching arrangements. (iii) Subjects were excluded who did not meet the experimental requirements by questionnaire. For example, those who have had a major impact on their own development because of family or other factors, as well as those who did not complete the experiment due to taking time off. (iv) The experimental assessor was separated from the researcher. In order to reduce the influence of subjective factors, the researcher only conducted 12 weeks of mindfulness training for the students throughout the experiment. The effect evaluation was supported by the class teacher and third party personnel (doctoral students) to conduct measurement and interview work before and after the experiment.

\section{Research Scenario}

The children's mindfulness education in this study is a self-regulation method that teaches children to be physically and mentally active. It is based on the adult mindfulness decompression method or the mindfulness cognitive therapy, and includes a series of courses based on the righteousness intervention program modified by the child's age teaching method. Because children's mindfulness cognitive therapy is for children with special needs, the course intervention of this study is aimed at the educational effectiveness of ordinary students. It should not be called therapy, but adapted to a kind of 
Table 1. Sample Statistics.

\begin{tabular}{lllllll}
\hline & Total \# & Boys & Girls & Valid \# & Boys & Girls \\
\hline Experimental Group & 31 & 20 & 11 & 26 & 15 & 11 \\
\hline Control Group & 31 & 19 & 12 & 29 & 17 & 12 \\
\hline
\end{tabular}

suitable mindfulness education program for the learning and education of general students. Therefore, in the design of the mindfulness education curriculum, we developed a 12-week course of mindfulness education based on the curriculum structure of foreign children's mindfulness cognitive therapy and children's mindfulness decompression therapy (Table 2). The experimental group received a 40-minute mindfulness education course once a week, had related homework, and the control group remained the same as they were before this experiment.

\section{Research Instruments}

\section{Measurement Scale}

The research instruments of this study include the Attention Stability Test Questionnaire, the Mental Health Rate Scale for Pupil (MHRSP), the Positive and Negative Affective Scale (PANAS), and the Index of Well-being (IWB).

(1) Attention Stability Test Questionnaire: The Attention Stability Test includes two parts, A and B, which consisting of multiple curves starting from the left side and ending on the right side, requiring participants to trace a curve from the left with eyes, and filling the number at the beginning of the curve into the square at the end of the curve on the right. Pens or fingers cannot be used as assistance in the whole test, and the correct response number is used as an evaluation index for attention stability. A study by Yin Hengchan in 2003 showed that the test had good validity (Yin, 2003).

(2) Mental Health Rate Scale for Pupil (MHRSP): This scale is a psychological test questionnaire consisting of 80 items. Every 10 items constitute a subscale, which in turn includes 8 subscales such as learning disabilities, emotional disorders, personality defects, social adaptation disorders, moral defects, behavior disorder and special disorders. The project adopts a three-level scoring system. Each project has three levels of "no", "occasionally" and "frequently", with 0 point, 1 point and 2 points in turn. The whole scale is the sum of the scores of each subscale. The higher the score is, the more the mental health problems there are, the lower the psychological level is.

(3) Positive and Negative Affective Scales: This scale is compiled by Watson (1988) and is currently the most widely used positive emotion measurement tool. It consists of 20 words that describe different sentiment and emotion. It is divided into Positive Affect (PA) and Negative Affect (NA). Two dimensions, each with 10 words. Chinese scholars have studied the applicability of the Chinese version of the scale in China and the cross-cultural consistency between China and the United States. The results show that the scale is suitable for the Chinese population, with cross-cultural con- 


\section{Table 2. Children's Mindfulness Education Course.}

\begin{tabular}{|c|c|c|c|}
\hline Time & Course Theme & Course Content & Homework \\
\hline Week 1 & $\begin{array}{l}\text { What is righteous thought: a gift } \\
\text { to accompany a lifetime }\end{array}$ & $\begin{array}{l}\text { Self-introduction; es- } \\
\text { tablishing norms; con- } \\
\text { sciously aware of non- } \\
\text { judgment }\end{array}$ & Mindfulness exercise \\
\hline Week 2 & $\begin{array}{l}\text { Breathing righteous thoughts: } \\
\text { experience breathing as an } \\
\text { anchor point, come back after } \\
\text { each distraction, and observe } \\
\text { breathing as a way to cope with } \\
\text { difficulties }\end{array}$ & $\begin{array}{l}\text { Lie, stand, sit and } \\
\text { breathe }\end{array}$ & $\begin{array}{l}\text { Number breath } 10 \\
\text { times before going to } \\
\text { bed }\end{array}$ \\
\hline Week 3 & $\begin{array}{l}\text { Mindfulness diet: the automatic } \\
\text { guidance of the thinking in the } \\
\text { process of eating }\end{array}$ & $\begin{array}{l}\text { Mindfulness eating } \\
\text { raisins; mindfulness } \\
\text { eating }\end{array}$ & $\begin{array}{l}\text { Mindfulness diet rec- } \\
\text { ord; Number of } \\
\text { breaths } 20 \text { times } \\
\text { before going to bed }\end{array}$ \\
\hline Week 4 & $\begin{array}{l}\text { Mindfulness Awareness: dis- } \\
\text { covering and breaking through } \\
\text { inertia thinking }\end{array}$ & $\begin{array}{l}\text { The attributes of the } \\
\text { five senses as the } \\
\text { object of awareness }\end{array}$ & $\begin{array}{l}\text { Number of breaths } \\
20 \text { before going to } \\
\text { bed }\end{array}$ \\
\hline Week 5 & $\begin{array}{l}\text { Body scan: awareness exercis- } \\
\text { es of static body }\end{array}$ & $\begin{array}{l}\text { Consciously aware of } \\
\text { various parts of the } \\
\text { body successively }\end{array}$ & $\begin{array}{l}\text { Mindful awareness } \\
\text { exercise; Number of } \\
\text { breaths } 20 \text { times } \\
\text { before going to bed }\end{array}$ \\
\hline Week 6 & $\begin{array}{l}\text { Mindfulness sit-in: awareness } \\
\text { exercise from the inside out }\end{array}$ & $\begin{array}{l}\text { Mindfulness, breath- } \\
\text { ing, body, thinking, } \\
\text { emotions, behavior, } \\
\text { etc. }\end{array}$ & $\begin{array}{l}\text { Number of breaths } \\
20 \text { times before go- } \\
\text { ing to bed }\end{array}$ \\
\hline Week 7 & $\begin{array}{l}\text { Mindfulness stretching: dynamic } \\
\text { body awareness exercises }\end{array}$ & $\begin{array}{l}\text { Learn to be aware of } \\
\text { the body through ac- } \\
\text { tion; mindfulness yoga }\end{array}$ & $\begin{array}{l}\text { Animal and plant } \\
\text { posture }\end{array}$ \\
\hline Week 8 & $\begin{array}{l}\text { Mindfulness walking: dynamic } \\
\text { exercises from the outside to } \\
\text { the inside, keeping awareness } \\
\text { during walking }\end{array}$ & $\begin{array}{l}\text { Walking indoors and } \\
\text { outdoors, experience } \\
\text { the feeling of your feet }\end{array}$ & $\begin{array}{l}\text { Number of breaths } \\
20 \text { times before go- } \\
\text { ing to bed }\end{array}$ \\
\hline Week 9 & $\begin{array}{l}\text { Mindfulness Listening: exploring } \\
\text { the interpersonal communica- } \\
\text { tion of mindfulness }\end{array}$ & $\begin{array}{l}\text { Harmonious relation- } \\
\text { ship; Listening to the } \\
\text { sound: no choice to } \\
\text { detect }\end{array}$ & $\begin{array}{l}\text { Learn to listen and } \\
\text { express; friendly wish } \\
\text { list }\end{array}$ \\
\hline Week10 & $\begin{array}{l}\text { Mindfulness life: my thoughts, } \\
\text { feelings, physical feelings, be- } \\
\text { havior }\end{array}$ & $\begin{array}{l}20 \text { minutes of medita- } \\
\text { tion practice; explore } \\
\text { the implementation of } \\
\text { mindfulness life }\end{array}$ & $\begin{array}{l}\text { Daily practice such } \\
\text { as brushing, bathing, } \\
\text { etc.; Number of } \\
\text { breaths } 20 \text { times } \\
\text { before going to bed }\end{array}$ \\
\hline Week 11 & $\begin{array}{l}\text { The Road to Mindfulness: intro- } \\
\text { spect and review personal } \\
\text { growth }\end{array}$ & $\begin{array}{l}\text { Introspective medita- } \\
\text { tion; share the process } \\
\text { through narrative }\end{array}$ & $\begin{array}{l}\text { Write a letter to your- } \\
\text { self }\end{array}$ \\
\hline Week 12 & Love: thanksgiving practice & Blessing & Self-practice \\
\hline
\end{tabular}


sistency and good reliability and validity (Zhang \& Yan, 2004).

(4) Index of Well-being (IWB): This scale was compiled by Campbell et al. in 1976. The scale includes two subscales: the Life Satisfaction Questionnaire and the Overall Affective Index. IWB has 9 questions; Overall Affective Index has 8 questions; the life Satisfaction Questionnaire has 1 question; the project uses 7 points; the total score is the sum of the scores of the life satisfaction questionnaire and the average score of the Overall Affective Index. Li Jing et al. revised the scale. After research, it was found that the correlation between the Overall Affective Index and the Happiness Survey was 0.53 , and the consistency between the Overall Affective Index and Life Satisfaction was 0.56 , which could be used as a tool to measure the happiness index ( $\mathrm{Li}$ et al., 2000).

The measurement process is strictly carried out in accordance with the procedures of psychological measurement. The main test is to issue and collect questionnaires on site one week before and one week after the experiment, and to unify the instructions. Students are required to carefully fill out the questionnaire according to their actual situation, in order to ensure the recovery rate and efficiency of the questionnaire, the whole process of the questionnaire test is carried out under the joint supervision of the researcher and the class teacher to ensure the authenticity and scientificity of the data.

\section{Qualitative Research Instruments}

The qualitative research instruments we developed of this study include the Mindfulness Experience Log Sheet, the Homework Log Sheet, the Open Questionnaire, and the Interview Outline.

The Mindfulness Experience Log Sheet is made by children to record their experiences and feelings during the implementation of the course. For example, what do you think about? What physical feelings are you concerned about? What emotions and feelings have you experienced? The content is designed to match the weekly teaching activities. At the end of each course, the children fill in the forms themselves to understand their learning state, as a reference for correcting teaching, and also as a source of research for researchers.

The Homework Log Sheet: After the course, the children go home to complete the Homework Log Sheet. The content design is also matched with the weekly teaching activities. The ideas, feelings, thoughts, affects, words and deeds, etc. perceived in each exercise are recorded. The researcher conduct family work every week. Reviewing the assignments and give appropriate guidance and encouragement to form a quality of mindfulness and better integrate mindfulness into life.

The Open Questionnaire: In addition, the researcher compiled a questionnaire and presented the interview questions in the form of a questionnaire to gain a more comprehensive understanding of the experiment results.

Finally, the researcher conducted formal interviews or random interviews on children during the experiment. The formal interview was based on the interview outline prepared in advance to obtain the overall perception of children in the teaching of 
mindfulness courses. Random interviews paid more attention to the real feelings during class, through the perspective of individual differences, to obtain children's different views on mindfulness education curriculum.

\section{Data Processing}

Using SPSS 20.0, the researcher analyzed the results of attention stability test questionnaire, mental health scale, positive and negative emotion scale, happiness scale, etc. in this study. The statistical analysis method used in this study can meet the research needs.

\section{Results and Analysis}

Through the comparative analysis of the difference results of pre-test and post-test between the experimental group and the control group and the results of pre-test and posttest of experimental group, we found that mindfulness education has extremely significant effects in promoting children's attention development, mental health development, emotional balance, and happiness.

\section{Analysis of Homogeneity Test Results between the Experimental Group and the Control Group}

In order to test whether the two groups were homogeneous, the independent sample T test was used to examine the difference of pre-test. The results showed that there was no statistically significant difference between the experimental group and the control group in the Attention Stability Test, Mental Health Rate Scale for Pupil, Positive and Negative Emotion Scales, and the Index of Well-being (Table 3). Therefore, students in these two classes can be used as an experimental group and a control group.

\section{Analysis of the Difference between the Results of the Experimental Group and the Control Group Before and After the Experiment}

According to the independent sample $\mathrm{T}$ test, it can be seen from Table $\mathbf{4}$ that there is a statistically significant difference in the scores of the Attention Stability Test between the experimental group and the control group before and after the experiment $(\mathrm{p}=$ 0.003); the mean value of the difference of the experimental group before and after the Attention Stability Test $(M=4.31)$ was significantly higher than that of the control group ( $M=0.03$ ), indicating that the stability of the attention of the experimental group was better than that of the control group.

The mental health problems of the students in the mindfulness experimental group were significantly improved compared with the control group. There was a statistically significant difference in the total score of the Mental Health Rate Scale for Pupil $(\mathrm{p}=0.000)$, and the mean difference of the total score of the Mental Health Rate Scale for Pupil of the experimental group (post-test score minus pre-test score) $(\mathrm{M}=-9.27)$ was significantly larger than that of the control group $(\mathrm{M}=-1.48)$. It shows that the psychological improvement of the students in the experimental group, whether it is the 


\begin{tabular}{lll}
\hline Table 3. Homogeneity Test Results. & \\
\hline & $\boldsymbol{t}$ & $\boldsymbol{p}$ \\
\hline Attention Stability Test & -0.325 & 0.746 \\
\hline Mental Health Rate Scale for Pupil & -0.019 & 0.985 \\
\hline Positive Emotion Scale & 0.296 & 0.768 \\
\hline Negative Emotion Scale & -0.088 & 0.930 \\
\hline Index of Well-being & -0.228 & 0.821 \\
\hline
\end{tabular}

\section{Table 4. Comparison of the Difference.}

\begin{tabular}{|c|c|c|c|c|c|c|}
\hline \multirow{2}{*}{ Subscale } & \multicolumn{2}{|c|}{ Exp. $(n=26)$} & \multicolumn{2}{|c|}{ Ctrl. (n = 29) } & \multirow{2}{*}{$t$} & \multirow{2}{*}{$p$} \\
\hline & $M$ & $S D$ & $M$ & $S D$ & & \\
\hline AST A Test & 0.46 & 0.905 & -0.07 & 0.842 & -2.252 & 0.028 \\
\hline AST B Test & 3.85 & 7.103 & 0.10 & 0.724 & -2.824 & $0.007^{*}$ \\
\hline AST Total Test & 4.31 & 7.287 & 0.03 & 1.085 & -3.123 & $0.003^{*}$ \\
\hline MHRSP Learning Disability & -0.96 & 2.690 & -0.10 & 0.939 & 1.613 & 0.113 \\
\hline Emotional Disorder & -1.62 & 2.174 & -0.17 & 0.759 & 3.356 & $0.001^{* *}$ \\
\hline Personality Defect & -1.81 & 3.124 & -0.24 & 0.830 & 2.602 & $0.012^{*}$ \\
\hline Social Adaptation Disorder & -1.69 & 2.526 & -0.21 & 0.774 & 3.016 & $0.004^{* *}$ \\
\hline Moral Defect & -0.12 & 2.123 & -0.28 & 0.797 & -0.379 & 0.706 \\
\hline Bad Habit & -1.08 & 2.911 & -0.10 & 0.772 & 1.736 & 0.088 \\
\hline Behavior Disorder & -1.85 & 2.694 & -0.21 & 0.819 & 3.123 & $0.003^{\text {*t }}$ \\
\hline Special Obstacle & -0.15 & 1.736 & -0.17 & 0.658 & -0.053 & 0.958 \\
\hline MHRSP Total Score & -9.27 & 8.263 & -1.48 & 2.278 & 4.877 & $0.000^{* *}$ \\
\hline Positive Emotion & 4.54 & 8.353 & 0.17 & 0.928 & -2.798 & $0.007^{* *}$ \\
\hline Negative Emotion & -2.65 & 6.066 & -0.31 & 0.850 & 2.060 & $0.044^{*}$ \\
\hline Overall Emotion Scale & 4.58 & 8.941 & 0.17 & 1.256 & -2.627 & $0.011^{*}$ \\
\hline $\begin{array}{l}\text { Life Satisfaction Question- } \\
\text { naire }\end{array}$ & 0.73 & 0.919 & 0.03 & 0.944 & -2.765 & $0.008^{* *}$ \\
\hline Overall Affective Index & 5.31 & 8.749 & 0.21 & 1.656 & -3.082 & $0.003^{*}$ \\
\hline
\end{tabular}

Note: ${ }^{*} p<0.05,{ }^{* *} p<0.01,{ }^{* *} p<0.001$; the higher the mental health score, the more negative psychological state; the higher the negative emotion score, the worse the mood. The same below. Exp.: Experimental group; Ctrl.: Control group.

overall level or mental health, personality defects, adaptation disorders and behavioral disorders, is significantly ahead of the control group after the mindfulness training. The results of the mindfulness education experiment are very significant. There are no statistical differences in mental health, including learning disabilities, moral defects, bad behavior, and mental disorders.

Before and after the experiment, the difference between the Positive and Negative Emotion Scales of the experimental group and the control group was statistically significant ( $\mathrm{p}=0.007 ; \mathrm{p}=0.044)$. The mean value of the difference before and after the Positive Emotion Scale test of the experimental group $(M=4.54)$ was significantly 
larger than that of the control group $(\mathrm{M}=0.17)$; the mean value of the difference before and after the Negative Emotion Scale of the experimental group $(\mathrm{M}=-2.65)$ was significantly smaller than that of the control group $(M=-0.31)$. It shows that the mindfulness education experiment can effectively promote children's emotional development.

The Index of Well-being indicates that mindfulness education is effective for improving student well-being. There was a significant difference in the scores of happiness before and after the test between the experimental group and the control group $(\mathrm{p}=$ $0.003)$. The mean difference of pre-test and post-test of happiness in the experimental group $(M=5.31)$ was significantly higher than that of the control group $(M=0.21)$.

\section{Comparison between Pre-Test and Post-Test Results of the Experi- mental Group}

After performing the paired sample $\mathrm{T}$ test for the data of rating scale of attention (AST) in the experimental group before and after the test, the results showed (as shown in Table 5): there was a significant difference between the overall data of attention between pre-test and post-test $(\mathrm{p}=0.006)$, and the total average score of post-test of attention ( $\mathrm{M}$ $=32.65$ ) was significantly higher than the total average score of the pretest of attention $(M=28.35)$; the A and B subtests also obtained the same result.

The average score of the experimental group's post-test on mental health (MHRSP) is significantly different from that of pre-test $(p=0.000)$, and the average score of mental health in post-test was nearly 10 points less than that of the pre-test, indicating that the mindfulness education largely promotes students' development of mental health. Specifically, the mindfulness education has different degrees of influence on the various dimensions of students' mental health. According to the extent of effects by the mindfulness education, those dimensions can be successively arranged from top to the bottom in such order as behavioral disorders, personality defects, social adaptation disorders, emotional disorders, bad habits, and learning disabilities.

After analyzing the data of the Positive and Negative Emotion Scales of the experimental group after the experiment, it can be seen that there are significant differences between the positive and negative emotions $(\mathrm{p}=0.010)$, and the total average score of post-test of the Positive Emotion Scale are 4.53 points higher than that of the pretest. The total average score of the Negative Emotion Scale of post-test is 2.65 points lower than that of the pretest. It shows that mindfulness education can enable students to gain more positive emotions and to promote the transformation from negative emotions to positive emotions.

The students in the experimental group have got better emotions. The scores of the Overall Affective Index were statistically significant $(\mathrm{p}=0.015)$, and the total average scores of the overall emotional index of post-test $(M=43.31)$ were significantly higher than the total average scores of the Overall Affective Index of pretest; the scores of the Life Satisfaction Questionnaire of pretest and post-test were significantly different $(\mathrm{p}=0.000)$, and the total average score of post-test $(M=5.42)$ was higher than that of the pretest $(\mathrm{M}=4.69)$; the total scores of the Index of Well-being of pretest and posttest were statistically significant $(\mathrm{p}=0.005)$, and the average score of the post-test of 


\begin{tabular}{|c|c|c|c|c|c|c|}
\hline \multirow{2}{*}{ Subscale } & \multicolumn{2}{|c|}{ Pre-test } & \multicolumn{2}{|c|}{ Post-test } & \multirow{2}{*}{$t$} & \multirow{2}{*}{$p$} \\
\hline & $M$ & $S D$ & $M$ & $S D$ & & \\
\hline AST A Test & 9.46 & 0.859 & 9.92 & 0.392 & -2.601 & 0.015 \\
\hline AST B Test & 18.88 & 8.788 & 22.73 & 3.915 & -2.761 & 0.011 \\
\hline AST Total Test & 28.35 & 9.082 & 32.65 & 4.009 & -3.014 & 0.006 \\
\hline MHRSP Learning Disabilities & 4.85 & 3.283 & 3.88 & 2.422 & 1.822 & 0.080 \\
\hline Emotional Disorders & 6.15 & 1.515 & 4.54 & 1.392 & 3.789 & $0.001^{*}$ \\
\hline Personality Defects & 6.54 & 3.455 & 4.73 & 3.471 & 2.950 & $0.007^{*}$ \\
\hline Social Adaptation Disorders & 5.35 & 1.573 & 3.65 & 2.591 & 3.416 & $0.002^{*}$ \\
\hline Moral Defect & 2.65 & 1.788 & 2.54 & 1.944 & 0.277 & 0.784 \\
\hline Bad Habits & 4.27 & 4.035 & 3.19 & 2.698 & 1.886 & 0.071 \\
\hline Behavioral Disorders & 6.15 & 2.444 & 4.31 & 2.363 & 3.495 & $0.002^{*}$ \\
\hline Special Obstacle & 3.19 & 2.713 & 3.04 & 2.615 & 0.452 & 0.655 \\
\hline MHRSP Total Score & 39.15 & 11.471 & 29.89 & 13.382 & 5.720 & $0.000^{*}$ \\
\hline Positive Emotion & 30.12 & 9.905 & 34.65 & 8.275 & -2.770 & 0.010 \\
\hline Negative Emotion & 22.92 & 8.275 & 20.27 & 7.102 & 2.231 & $0.035^{*}$ \\
\hline Overall Emotion Scale & 38.73 & 8.586 & 43.31 & 6.078 & -2.610 & 0.015 \\
\hline Life Satisfaction Questionnaire & 4.69 & 0.970 & 5.42 & 0.987 & -4.055 & 0.000 \\
\hline Overall Affective Index & 43.42 & 8.650 & 48.73 & 6.472 & -3.093 & $0.005^{*}$ \\
\hline
\end{tabular}

Table 6. Correlation Analysis of Total Scores of Attention, Mental Health, Positive and Negative Emotions, and Happiness (Pearson).

\begin{tabular}{llllll}
\hline & $\mathbf{1}$ & $\mathbf{2}$ & $\mathbf{3}$ & $\mathbf{4}$ & $\mathbf{5}$ \\
\hline 1 Attention & - & & & & \\
\hline 2 Mental Health & $-0.777^{* *}$ & - & & & \\
\hline 3 Positive Emotion & $0.690^{* *}$ & $-0.727^{* *}$ & - & - \\
\hline 4 Negative Emotion & $-0.658^{* *}$ & $0.687^{* *}$ & $-0.867^{* *}$ & - & - \\
\hline 5 Happiness & $0.767^{* *}$ & $-0.818^{* *}$ & $0.727^{* *}$ & $-0.781^{* *}$ & - \\
\hline Note: ${ }^{* *}$ significantly correlated at .01 level (two-tailed) & & & \\
\hline
\end{tabular}

the Index of Well-being was 5.31 points higher than that of the pretest.

\section{Correlation Analysis Results}

Pearson Product-moment correlation was used to analyze the difference between attention, mental health, positive emotion and negative emotion, and happiness. The correlation between each variable is shown in Table 6. It can be seen that there is a significant positive correlation between attention and happiness $(r=0.767)$, positive emotions $(r=$ 0.690); there is a significant negative correlation between attention and negative emotions, mental health. There is a significant negative correlation between mental health 
and attention, positive emotions, and happiness; there is a significant positive correlation between mental health and negative emotions. There is a significant positive correlation between happiness and positive emotions; there is a significant negative correlation between happiness and negative emotions. There is a significant negative correlation between positive emotion and negative emotion. It shows that when children's attention is developed, their psychological barriers decrease, positive emotions increase, and happiness increases. Once children's psychological disorders and negative emotion decrease, then their attention, positive emotions, and sentiment will develop. As children's emotional index and happiness increase, their negative emotions decrease, positive emotions increase, and their psychology tends to develop well.

\section{Conclusions and Implications}

According to the above analysis, the mindfulness education experiment promotes the children's attention development, mental health development, social development, emotional balance and development, happiness improvement, and also has an interactive effect, thereby promoting the overall development of children.

In this study, mindfulness education can improve children's attention stability and significantly improve their attention development. In the questionnaire, student $S$ wrote, "When I am distracted, I can accept it and turn my attention back." Student L said, "I copied the text from the first row to the third row before, but I don't do this now." Undoubtedly, mindfulness education can significantly reduce students' learning pressure and improve their mental health. However, this study only found that the effects on emotional disorders, personality defects, social adaptation disorders and behavior disorders in mental health were significant; the effects on learning disabilities, moral defects, bad habits and mental disorders were not obvious, but according to interviews and questionnaires, mindfulness education has an effect on children's learning disabilities, morality and bad habits to some extent. For example, student G said, "When I write homework, I can write it more quietly. I made many mistakes before, but now I can get an A for many times." student D said frankly, "When I do homework or write words, I can write with mindfulness. When I can't solve the problem, I can calculate it with a pen seriously." It explains that through mindfulness education children can develop good habits.

This experimental study also proves that cultivating students to master the method of mindfulness through mindfulness education can make them control and evade negative emotions, gradually observe and feel the novelty and beauty of the present life, understand thoroughly the happiness contained in the depths of the soul, and thereby, the experience of positive emotions can be strengthened and gathered. In addition, the study also finds that the improvement of the level of mindfulness plays a significant mediating role in improving the effect of happiness, which is consistent with the research results of the researchers (Xu et al., 2015; Liu et al., 2013) and also with the qualitative findings of this study. For example, student W said, "I changed a lot after taking the mindfulness class, from fear to calm, from impatient to tolerant. I am more 
patient with things." "When I am angry and unhappy, I can breathe and calm down. When I take the mindfulness class, I feel very happy. Mindfulness adds color to my life." According to the above analysis, this experiment has achieved certain results and can provide some guidance for the practice of mindfulness education. However, if we want to ensure that mindfulness education plays a positively leading role in the children development, we need to do the following work.

\section{(1) Raising Awareness, Actively Creating Conditions, and Appropriately Carrying Out Mindfulness Education}

Children are in a critical period of physical and mental development, with physical and psychological development and changes in study habits and school environment, they will face psychological problems affecting, interpersonal communication, personality development, self-awareness and the pressure of study and life. Through the findings, as a new form of school education, mindfulness education plays a unique role in promoting children's development and it is an effective way to achieve children's all-round development and healthy growth. This study has shown that children mindfulness education plays a significant role in regulating children's negative emotions and promoting children's happiness. In the state of mindfulness, the student's parasympathetic (relaxation) nervous system is maximally activated, and can experience a state of joy, peace, calmness, and happiness. In mindfulness education, techniques such as body scans, mindfulness sensory awareness, mindfulness movement, mindfulness breathing, etc. are guiding students to consciously think, pay attention to and extend the awareness of the present. Mindfulness emphasizes non-judgment and acceptance; it promotes children's cognitive reassessment, and creates the conditions in order to accept the current situation. All these attributes can cultivate deeper empathy and good qualities in children. Therefore, it is necessary to add more mindfulness education and training for children, improve the quality of mindfulness, and then can promote the all-round development and healthy growth of children.

\section{(2) Strengthening the Mindfulness Teaching Ability of Educators and Improving the Overall Development Level of Children}

When educators conduct mindfulness training for children, they should pay attention to guiding children to observe their physical or psychological feelings, so that children can learn to observe and accept their current state as much as possible without any evaluation, so as to guide the emotions and ideas to be expressed. The purpose of mindfulness education is not only to achieve the goals of the established educational activities, but more importantly, how to integrate the attitudes and methods of focusing on and understanding the mind and body experience, open acceptance, and non-judgment in the whole process of education and teaching. Therefore, the words and deeds of educators are the most direct demonstration of mindfulness to students. This requires educators to have mindfulness learning experiences and continuous mindfulness practices and further education. The most important thing is to be able to practice in daily life. Only when educators are aware of themselves can they constantly feel the needs of children 
to be in the "being mode," which in turn helps to accomplish improved educational achievement and the overall development level of children.

\section{(3) Drawing Nourishment from Related Mindfulness Projects and Lo- calizing Western Mindfulness Education}

Many countries in the West have established social institutions such as the "Mindfulness Education Association," "Mindfulness Education Network," and "School of Mindfulness" to actively apply mindfulness education within schools. For example, Nan Tien Institute (Australia) provides a special course for mindfulness, education transforming teachers' in-service training to enhance mindfulness teaching helping teachers better integrate "mindfulness" into specific teaching practices. In China's Taiwan region, the "Mindfulness Development Association" and the "Chinese Mindfulness Decompression Center" have also been established, where the positive mindfulness training practice has been actively carried out in the primary school life curriculum action research, and has achieved certain results. The development of mindfulness education projects such as these provides abundant nutrients for the orderly implementation of mindfulness education in mainland China.

However, any kind of educational theory is not a universally applicable truth, but has its relevance or cultural constraints. If the practice of mindfulness education is to be carried out in an orderly manner and achieve the expected results, it is necessary to construct a "localized" mindfulness education theory that is locally compatible, so as to provide theoretical support. To this end, we need to combine the Chinese national conditions, based on local situations and reality, to localize the Western mindfulness education theory This will encourage educators to actively carry out the exploration and practice of mindfulness education, to accomplish experiences and achievements, and construct a mindfulness education model with Chinese characteristics, thus creating conditions for laying the foundation to improve the development of children in China.

\section{Acknowledgements}

We would like to thank Professor Marc Shelton for providing helpful comments on earlier drafts, and made suggestions for further revisions. Despite such support, this article is bound to contain errors which are, of course, the entire responsibility of the authors.

\section{References}

Huang, F.Y. (2015) Children's mindfulness education. Nation Edu, (1):33.
Li, J. \& Zhao, Y.J. (2000) Campbell happiness scale for the test report of Chinese college students. Chin J Clin Psychol, 8(4):225-226. 
Liu, X.H., Xu, W. \& Wang, Y.Z. et al. (2013) A 6 -week randomized controlled trial of mindfulness training to improve the well-being of volunteers. Chin J Ment Health, 27(8):597601.

Xu, W., Wang, Y.Z. \& Liu, X.H. (2015) Effect of 8 weeks of mindfulness training on negative emotions. Chin J Ment Health, 29(7):497-501.

Yin, H.B. (2003) Research on adolescent attention test and evaluation index. Chin Sport Sci Tech, 39(3):51-53.
Zhang, J.H. (2004) The work guide for minors' physical and mental health and ideological and moral education (Volume I). Beijing:Contemporary China Audiovisual Press, 85.

Zhang, W.D. \&Yan, J. (2004) Cross-cultural psychological measurement of positive and negative emotions: A test of dimensional structure of PANAS. Psychol Sci, 27(1):77-

Received: 29 May 2019

Revised: 11 June 2019

Accepted: 09 July 2019

The Chinese version of this article has been published in Educational Research and Experiment 2018; 6:23-28. The English version has been authorized for being publication in BECE by the author(s) and the Chinese journal.

谢晶, 涂艳国. 正念教育对儿童发展影响的研究一基于武汉市某小学五年级的正念实验. 教 育研究与实验, 2018; 6:23-28. 